\title{
Constitutional and legal framework of environmental rights of citizens in the Russian federation
}

\author{
Alexander Savoskin, Oleg Kozhevnikov, and Tatyana Falkina \\ Ural State University of Economics, 8 March/Narodnaya Volya Str., 62/45, 620144 Ekaterinburg, \\ Russia
}

\begin{abstract}
The article analyzes the constitutional and legal foundations of the environmental rights of citizens, the problems of legal regulation of environmental legal relations. The article examines the key legal acts that are related to the implementation of environmental rights of citizens. The article analyzes the judicial practice in the sphere of application of environmental rights of citizens.
\end{abstract}

\section{Introduction}

At present, the role of a human and world civilization in nature, unfortunately, is accompanied by a developing ecological crisis, depletion of natural resources, and a threat to the state of the natural environment. Violation of environmental legislation, environmental terrorism, ecocide - all this raises an acute question of the preservation of a human as a biological species [9]. According to new data from the World Health Organization (WHO), 9 out of 10 people breathe air with a high concentration of pollutants (World Health Organization website // https://www.who.int/phe/ru/).

According to the Declaration on Environment and Development adopted by the United Nations Conference on Environment and Development (Rio de Janeiro, 3-14 June 1992), the right to development must be respected in a way that equitably meets the development and environmental needs of present and future generations (principle 3); in order to achieve sustainable development, environmental protection must be an integral part of the development process and cannot be considered in isolation from it (principle 4). In general, the issues of protecting the environmental rights of citizens are determined by a number of acts at the international level (the Stockholm Declaration was adopted in Stockholm on June 16, 1972 at the UN Conference on the Human Environment).

The right to a healthy environment is one of the basic natural human rights. This right, as well as the right to life, recognized by Article 20 of the Constitution of Russia, is a right given by nature itself. For the first time in Russia, or rather in the USSR, this right was enshrined in the Declaration of Human Rights and Freedoms, adopted in 1991. Congress of People's Deputies of the USSR, and later - in the Constitution of 1993.

The right to a healthy environment is one of the basic natural human rights. This right, as well as the right to life, recognized by Article 20 of the Constitution of Russia, is a right given by nature itself. For the first time in Russia, or rather in the USSR, this right was 
enshrined in the Declaration of Human Rights and Freedoms, adopted in 1991. Congress of People's Deputies of the USSR, and later - in the Constitution of 1993.

\section{Materials and Methods}

The publication is based on the analysis of the Constitution of the Russian Federation, international acts, normative acts of the President of the Russian Federation, the Government of the Russian Federation, materials of judicial practice and official statistical data (including reports of authorities and reports of scientific organizations prepared by orders of authorities), presented on the websites of the Ministry of Education and Science of the Russian Federation (https://minobrnauki.gov.ru), Ministry of Agriculture of the Russian Federation (https://mcx.gov.ru), Ministry of Natural Resources and Ecology of the Russian Federation (https://www.mnr.gov.ru), as well as on the materials of open data of federal executive authorities, posted in accordance with the Federal Law "On Providing Access to Information about the Activities of State Bodies and Local Self-Government Bodies".

Within the framework of this research, the optimal constitutional model of legal regulation of environmental rights is built on the basis of the dialectical unity of its legalsecurity and general scientific methods (analysis, synthesis, deduction and induction, abstraction, structural-functional method) and special methods of cognition (formal-legal, method of legal construction, formal-logical, system, technical-legal analysis, statistical method). On the basis of which, measures are proposed to improve the legal regulation of the subjective constitutional right to a favorable environment and the law enforcement practice of its implementation and restoration.

\section{Results and Discussion}

The analysis of the genesis of the constitutional norms reflecting the elements of the institution of environmental rights of man and citizen allowed Chalykh I. S. to distinguish three stages of their development in the Russian state: 1) the environmental stage (19181976); the ecological-integrative stage (1977-1992); the personality-oriented stage (1993BC) [8]. At the first stage, the state was becoming the main subject of environmental legal relations, and there were imperative methods of regulation. The second stage is characterized by the inclusion of citizens in environmental legal relations. The third stage is the consolidation of environmental human and civil rights in the Constitution of the Russian Federation as value priorities for the development of the state and society. At the third stage, there is a combination of imperative and dispositive methods of legal regulation.

Leading scientists in the field of constitutional law pay close attention to the analysis of the constitutional and legal foundations of environmental rights of citizens (S. A. Avakian, H. A. Bogdanova, N. V. Vitruk, L. D. Voevodin, G. A. Gadzhieva, O. E. Kutafin, E. I. Kozlova, E. A. Lukasheva, V. O. Luchin, B. A. Strashun, Yu.A. Tikhomirov). The subject of scientific analysis also became the features of the concept and content of environmental rights of man and citizen (O. L. Dubovik, E. I. Efimova, I. O. Nazarova, V. V. Petrov, T. V. Rednikova, A. A. Roerich, AL. Ryzhenkova, A. G. Tarnavsky, A. A. Tretyakova, O. V. Trudovaya, A. D. Ursula, A. E. Chernomorets, A. A. Yunusov.). Scientists pay special attention to the development of the institute of guarantees that are the basis for ensuring subjective environmental rights (O. K. Aliyev, V. N. Butylin, D. S. Veliyeva, Yu. E.Vinokurov, JI. A. Grigoryan, D. P. Dezhina, V. Yu.Emelyanov, A. B. Zaritsky, V. M. Zakharov, S. V. Kalashnikov, P. A. Kalinichenko, T. G. Kirlanov, A. B. Kurakin, R. G. 
Melnichenko, M. V. Morozova, I. A. Mukhin, A. E. Novikova, S. I. Nosov, G. I. Osipov, D. N. Ratsiborinskaya, M. S. Strogovich, O. I. Tiunov, JI. H.Fedorova, A. B. Chernykh, A. A. Yugov, A. E. Yastrebov). As a result of such intensive research activities, we can say with great confidence about the formation and development of a legal institution within the framework of constitutional law - the constitutional foundations of environmental rights of citizens, which includes: 1) norms defining the basis of the constitutional system in the field of ecology; 2) norms containing subjective environmental rights and environmental obligations; 3) norms defining the right of ownership of natural resources; 4) norms establishing the differentiation of the subjects of competence and powers of the Russian Federation and the subjects of the Russian Federation in the field of environmental legal relations; 5) norms providing for the powers of the highest state authorities in the field of regulation of environmental relations [6].

The classification of environmental rights of citizens formed by scientists is also of interest for the study, which looks like this:

1) rights that are aimed at meeting human needs at the expense of natural resources (the right to the natural environment and the right to use natural resources);

2) rights related to the protection of health from the adverse effects of the natural environment;

3) rights in the field of ensuring the observance and protection of the rights to a favorable environment and protection of health from the adverse effects of the environment;

4) the right of citizens to own natural resources [2].

At the same time, despite the dynamic development of the constitutional basis of environmental rights of the individual, it should be stated that until now the norms of legislation in the field of ecology and the environment have not been fully implemented [1]. This is facilitated by the low industrial, environmental and legal culture of Russian citizens, the presence of obvious defects in the legal consciousness and legal nihilism of Russian citizens.

In this regard, the state reports of the Ministry of Natural Resources and Ecology of the Russian Federation on the state and use of water resources are of interest; on the state and use of mineral resources, on the state of Lake Baikal and measures for its protection, etc. (Open data of the Ministry of Natural Resources and Environment of the Russian Federation // https://www.mnr.gov.ru)

According to the results of environmental monitoring carried out by Roshydromet, the largest part of the population lives in technogenically contaminated areas, which is associated with the growth of urbanized areas, emissions from an increasing number of vehicles, as well as ineffective treatment of emissions and discharges at industrial enterprises. According to the report of the Russian Federation "On the sanitary and epidemiological state of the population for 2019" of the Federal Service for Supervision of Consumer Rights Protection and Human Wellbeing, significant reasons that form the state of sanitary and epidemiological well-being and health of the population were sanitary and hygienic (chemical, biological, physical) factors with an approximate number of exposed population and a more pronounced impact on health - 93.4 million people in 52 constituent entities of the Russian Federation 64\%.

So, only the prosecutors of the Krasnoyarsk Territory at the end of 2019 revealed more than 10 thousand violations of the legislation on environmental protection and nature management, in order to eliminate which, about 5 thousand acts of response were adopted, more than 2 thousand persons were brought to administrative and disciplinary responsibility. As directed in the order of clause 2, part 2 of Art. 37 of the Code of Criminal Procedure of the Russian Federation, 94 criminal cases were initiated (open data on the 
website of the General Prosecutor's Office of the Russian Federation https://genproc.gov.ru).

The Constitutional Court of the Russian Federation in its decisions has repeatedly noted that "the constitutional obligation to preserve nature and the environment, to take good care of natural resources is universal and applies to both citizens and legal entities, which necessarily implies their responsibility for the state of the environment. The public authorities, which are also constitutionally responsible for the preservation of nature and the environment, are obliged to take measures aimed at curbing environmental pollution, preventing and minimizing environmental risks "(for example, Resolution of the Constitutional Court of the Russian Federation of March 5, 2013 No. 5-P). In the implementation of the ecological function of the state, all state authorities and local selfgovernment bodies are involved in one way or another, since ensuring favorable environmental conditions for the life of the entire population is one of the guarantees of the further existence of Russian society and the state as a whole.

In this regard, the legal, organizational and financial foundations of state policy in the field of ensuring constitutional environmental rights should be aimed at preserving nature and the environment, and when using natural resources in solving their socio-economic tasks by business entities, it was ensured as a balance of interests of economic and other entities. and the interests of the individual and society as a whole, and the observance and protection of the environmental rights of citizens was guaranteed.

To implement the specified state policy to ensure constitutional guarantees for observing the environmental rights of citizens and preserving the natural environment, it is necessary to significantly update the environmental regulatory legal framework, which provides for effective tools to increase the efficiency of environmental legal acts. One of these tools that have shown their effectiveness is the application of property liability for violation of legislation in the field of environmental protection. Directive 2004/35 / CE of the European Parliament and of the Council of the European Union of April 21, 2004 "On environmental liability aimed at preventing environmental damage and eliminating its consequences" indicates that the establishment of such liability is necessary to encourage business owners to take measures to develop technologies, allowing to minimize the risk of environmental damage. It should be noted that a specific feature of property liability for violation of legislation in the field of environmental protection is that harm, as a necessary condition for the composition of an offense, is caused not to the property of a specific person, but to the environment, defined as a set of components of the natural environment, natural and natural-anthropogenic objects. that are used or can be used in the implementation of economic and other activities as sources of energy, production products and consumer goods and have consumer value, as well as man-made objects. Compensation for harm in such cases is aimed primarily at overcoming these consequences and restoring the disturbed state of the environment to the maximum extent possible. As the application of measures of property liability for causing harm to natural objects, one can cite the decision of the Arbitration Court of Krasnoyarsk dated February 12, 2021 on the collection of 146.2 billion rubles from NTEK JSC. for environmental damage from the accident. On May 29, 2020, at CHPP-3, owned by the structures of MMC Norilsk Nickel, the supports of the tank in which the diesel fuel was stored sagged and partially collapsed, resulting in a diesel spill with a volume of 21 thousand tons [5].

Another effective mechanism for ensuring constitutional guarantees of the observance of the environmental rights of citizens is to increase the environmental awareness and culture of citizens.

We, the inhabitants of Russia, who perceive the vast expanses of their country as an unconditional reality, find it difficult to seriously believe that a reckless attitude towards natural resources can make the natural environment at first of little use and then impossible 
for living. A significant number of citizens of the Russian Federation still believe that "only specialists should be engaged in environmental activities, nothing will change from my participation." This attitude ("environmental prejudice") prevents them not only from participating in environmental activities, but also leads to ignoring information related to environmental problems. People do not study environmental issues and are not interested in receiving environmental education. In our opinion, it is obvious that it is citizens who should be widely involved in issues and measures for the protection of the natural environment. At the same time, public authorities and local self-government bodies must constantly create conditions and direct the efforts of proactive citizens and organizations to the implementation and protection of environmental rights.

\section{Conclusions}

Stable and progressive development of any modern society presupposes a reasonable balance between meeting the needs of people, improving their quality of life while maintaining proper conditions for future generations and the careful use of the Earth's resources (especially those that are not replenished) [3]. Development of the economy The preservation of the natural environment must be carried out in such a way that it is not accompanied by dangerous pollution and destruction of the natural environment. This is what not only the special provisions of Art. 42 of the Constitution of the Russian Federation that everyone has the right to a favorable environment, but also the norms of Art. 9 that "land and other natural resources are used and protected in the Russian Federation as the basis of the life and activities of the peoples living in the corresponding territory." All this requires constant improvement and an integrated approach in the constitutional and legal regulation of environmental relations, increasing the role and importance of legal instruments for protecting public and state environmental interests [4], "as the most important type of public interests protected by law" [7].

\section{References}

1. E.Yu. Balayan, Bulletin of Omsk State University, 1, 59 (2020)

2. T.V. Volkova, Bulletin of Tomsk State University, 35, 164 (2020)

3. N.V. Gorbachev, Issues of State and Municipal Administration, 2, 85 (2020)

4. E.V. Balatsky, N.A. Ekimova, The Manager, 12(1), 18 (2021)

5. A.V. Dolzhikov, Bulletin of Tomsk State University, 36, 56 (2020)

6. V. Malecki, Bulletin of Tomsk State University, 35, 186 (2020)

7. A.O. Minyaev, Constitutional Foundations of Environmental Law (2004)

8. N.A. Tretyakov, International Journal of Humanities and Natural Sciences, 2-3 (53) (2021)

9. I.S. Chalykh, Constitutional and legal guarantees of subjective environmental rights (2010)

10. M.U. Khairutdinov, Bulletin of Tomsk State University, 36, 203 (2020) 